\title{
AC 2012-3490: MULTICULTURAL ENGINEERING RECRUITMENT AND RETENTION AT A LARGE URBAN UNIVERSITY
}

\section{Dr. Katherine S. Zerda, University of Houston}

Kathy Zerda is the Director of the Program for Mastery in Engineering Studies (PROMES), the multicultural learning community for undergraduates at the Cullen College of Engineering. She also directs the UH Women in Engineering program. Zerda is an Instructional and Research Assistant Professor for the college and serves as the faculty adviser for the student chapters of the Society of Women Engineers and the Society of Mexican American Engineers and Scientists. Before joining the University of Houston, Zerda worked as an Engineering Manager for Hewlett-Packard Company. She earned the bachelor's of science degree from the University of Notre Dame, her Ph.D. from Baylor College of Medicine, and a master's in business administration from Mays Business School at Texas A\&M University. Zerda represents the University of Houston on the board of the Texas Alliance for Minorities in Engineering (TAME) and serves as current Board Chair.

\section{Dr. Stuart A. Long, University of Houston}

Stuart A. Long was granted B.A. and M.E.E. degrees in electrical engineering from Rice University, Houston, Texas, in 1967 and 1968, respectively, and a Ph.D. degree in applied physics from Harvard University, Cambridge, Mass., in 1974. He joined the faculty at the University of Houston, and served as Chairman of the Department of Electrical and Computer Engineering from 1984 to 1995 and as Associate Dean of the College of Engineering from 1995 to 2008. He was Interim Dean of the Honors College in 2008-2009. He also serves as Associate Dean of Undergraduate Research and the Honors College, and in this role oversees the undergraduate research programs for the entire campus. He is a professor in the Department of Electrical and Computer Engineering and a registered Professional Engineer. In 2010-2011, he served as Interim Vice Chancellor/Vice President for Research and Technology Transfer.

\section{Dr. Fritz J. Claydon, University of Houston}




\section{Multicultural Engineering Recruitment and Retention at a Large Urban University}

\section{Introduction}

The University of Houston serves a diverse population of students including many FirstGeneration-in-College (FGIC) students and many from groups traditionally underrepresented in the engineering workforce. Students who enroll in engineering generally must work to finance their education. As a result, four-year graduation rates are low, especially among African American and Hispanic students. To address the issue of low participation and low success for students of color, particularly women, in engineering fields, the college has developed a multicultural learning community framework with a number of related support structures. This learning community is named the Program for Mastery in Engineering Studies (PROMES) and represents the Multicultural Engineering Program (MEP) for the university. Participation is voluntary and multidisciplinary, and the community numbers approximately 500 undergraduates, i.e. $15-20 \%$ of the total population of engineering undergraduates. This integrated framework of recruitment and retention activities supports the college of engineering's mission of increasing student participation and student success among underrepresented groups.

The scope of programs within this multicultural community framework includes unique outreach collaborations with local school districts, nonprofits, and corporations to expose youngsters to exciting math, science, and engineering design activities led by engineering undergraduates. It also includes a residential summer engineering program for precollege students and their undergraduate engineering student mentors. Once admitted to engineering, incoming college students gain access to a system of academic Best Practices that includes first-year common cohorts for math, science and engineering courses, collaborative learning workshops, academic success tools, personal skills enhancement, formalized peer mentoring, and service learning. Returning and transfer students access supplemental collaborative learning workshops in support of sophomore- and junior-level engineering courses. These are peer-led problem-solving sessions that meet for three hours each week to reinforce concepts from difficult lecture courses such as Circuit Analysis, Thermodynamics, Statics, Applied Electromagnetics, and Chemical Processes. This model -- building cohorts of students in common courses, bringing engineering undergraduates into active leadership roles in building a community of scholars, instilling a value of "reaching back" to encourage precollege students to pursue high education, placing upper division students into peer mentoring relationships with incoming students, emphasizing academic Best Practices at all levels, and empowering students through peer-led supplemental instruction in high failure rate sophomore and junior engineering courses - has proved successful in retaining at-risk students who might otherwise not persist in engineering.

Recruiting and Outreach: Increasing Participation of Under-represented Groups in Engineering Education

Our college goals emphasize increasing participation in engineering higher education, especially among African American and Hispanic populations. PROMES faculty and staff lead the college mission of encouraging area youth (especially those from low-income and under-represented groups) to pursue higher education in engineering and related STEM fields. We work with area 
middle and high school administrators, teachers, students and corporate partners throughout the year to provide peer mentoring at the schools, on-campus college experiences, and fun science and math events to excite students about higher education and careers in science and engineering fields.

PROMES has only a small fulltime staff, so we have developed a unique framework to maximize our financial and human resources. This framework reflects a partnership between our program office and five multidisciplinary student engineering societies who also have engineering outreach goals. Program staffers serve as university advisors for all five organizations which include the Society of Women Engineers (SWE), Society of Hispanic Professional Engineers (SHPE), National Society of Black Engineers (NSBE), Society of Mexican American Engineers and Scientists (MAES), and Engineers Without Borders (EWB). In order to maximize the impact of our individual efforts and to forge tight coordination between outreach efforts, we aligned our strategies two years ago. At that time the college co-located the leadership of all five student engineering societies so that they now share office and study space, placing them in close physical proximity with each other and with the general PROMES student community, many of whom are members of these societies as well. Each organization maintains an online Google Calendar, making it available to leaders of all of the other teams. Twice a month, student leaders meet together with program staff to plan and coordinate upcoming outreach events, discuss any concerns, and share organizational Best Practices. Each organization recruits volunteers from the greater multicultural student community, especially the freshmen/transfer student cohort enrolled in the program's first-year introductory engineering curriculum. This creates a framework of peer mentoring between upper division students and new members of the learning community, and also infuses a strong value of "reaching back" to serve youngsters in the community. Students immersed in the learning community do not see recruiting and retention as distinct efforts. Rather, they view these twin goals as intertwined themes aimed at developing a diverse future engineering workforce. They know that the learning community is there to support their personal success, and they enthusiastically join in efforts to encourage precollege youngsters who "look like them" to follow in their footsteps.

The outreach collaborator framework serves more than one thousand low-income area precollege school youngsters during each academic year. Undergraduate engineering students spend time at local middle and high schools with their protégés to assist rocketry and robotics teams or to help teachers with in-classroom pre-engineering activities. Other events take place at our university campus, giving parents, teachers and students the opportunity for an on-campus college experience. These latter activities include SWE's annual "Launch into Engineering", the MAES "Science Extravaganza", and SHPE's "Noche De Ciencias" college night. NSBE leads an annual "Walk for Education" event in a nearby low-income neighborhood, bringing college students and community youngsters together to promote education. Each fall PROMES partners with local independent school districts (ISDs) and local corporate partners to host an industry Career Day. During this event, industry engineers and scientists spend a Saturday with middle and high school students to explore technical careers. PROMES also hosts a multi-school competition for Houston ISD students featuring robotics, rocketry, mousetrap cars and engineering design activities. During each spring semester, the outreach collaboration team hosts middle and high school math and science contests in partnership with the Texas Alliance for Minorities in Engineering (TAME), Houston and other local ISDs and local corporations. 
Outreach and recruiting efforts continue into the summer each year with a precollege residential engineering immersion experience for rising high school seniors. Over the past ten summers the camp has served 520 students, $40 \%$ of whom are female. The participant profile over that same period is 38\% African American, 31\% Hispanic, 20\% White, 8\% Asian, and 3\% other $/ \mathrm{mixed}$. In recent years Facebook has been used as a means of linking past participants and is a convenient tool to informally track post-high school progress of campers with respect to their pursuit of STEM careers. The vast majority of students who attended the camp have continued their education post-high school and many are students in STEM majors currently at universities across the state and the nation. Our university has successfully recruited about $15 \%$ of camp participants annually into engineering degree programs. Corporate partners have funded scholarships for these students. We have also found that undergraduate engineering students who have served as camp counselors have persisted in their own educational goals and been energized through the camp experience and in their role as mentors.

Supporting a Diverse Population of Engineering Undergraduates to Graduation

PROMES programming includes several key components that support student success. The curriculum components integrate project-based learning and team-based design challenges with study skills development, time management strategies, and personal and professional skills enhancement. Those will be discussed in another paper that focuses on First Year programs. For the remainder of this paper we will present another cornerstone of our college's programs to support student success.

Far too often, students who enter college aspiring to careers in engineering progress successfully through their freshman courses but do not survive the rigorous sophomore courses. Some of the sophomore engineering courses (e.g. Thermodynamics, Mechanics I, Chemical Processes, Applied Electromagnetics and Circuit Analysis) have pass rates in the range of only 50\%. Our college enforces a two-attempt policy for engineering courses, meaning that students who do not achieve a $\mathrm{C}$ - average or higher in an engineering course within two attempts are not allowed to continue in their major. Withdrawals count as an attempt under this policy. This policy often translates into low rates of retention and persistence to graduation. To address this issue we offer course-specific supplemental problem-solving workshops that meet for three hours each week through the semester. Each workshop is facilitated by one or two peer mentors who have demonstrated competency in the course content. Each workshop serves up to 25 students. There is no charge to students who wish to participate, but regular attendance and active participation is mandatory. The workshop format promotes academic excellence and fosters leadership skills. Last year, 300 students enrolled in eleven workshops. Figure 1 shows pass rate data for six "gatekeeper" sophomore courses. Students in workshops fared better than their non-workshop peers in each of these courses, generally averaging between one-half and one full grade point higher, although results vary by course and also by semester.

Even in cases where pass rates are not significantly different between workshop participants and their non-participating peers (e.g. Chemical Processes), we see another unexpected impact of the workshop process. Workshop students have low course withdrawal rates compared with much higher rates for their non-workshop peers. Figure 2 shows withdrawal rates of students taking the same courses represented in Figure 1 during the 2011 academic year. The Chemical Processes course is an example of a course with traditionally low pass rates for all students, with 
a $50 \%$ pass rate for non-workshop participants and only a marginally higher pass rate of $57 \%$ for students enrolled in a workshop.

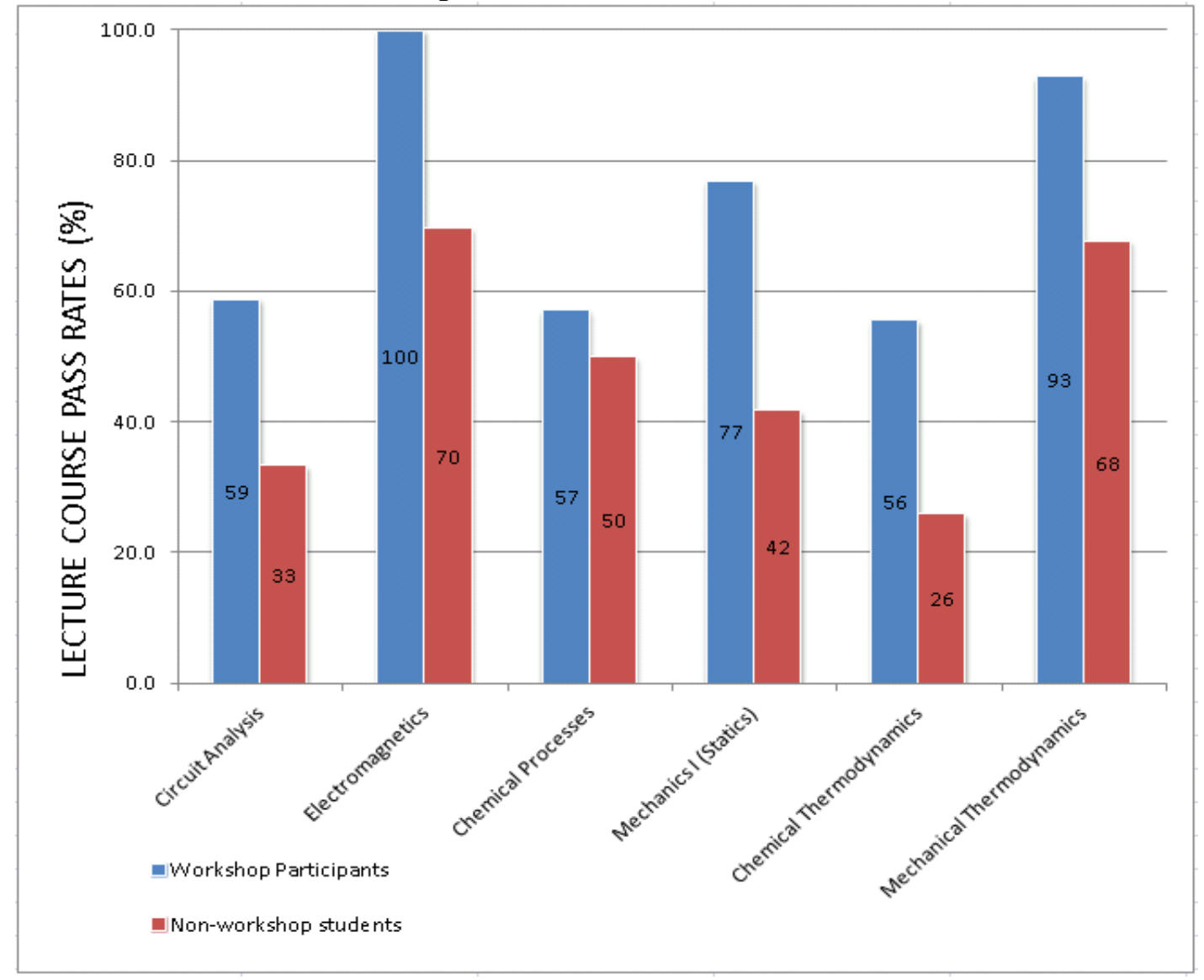

Figure 1. Pass rates of students enrolled in sophomore engineering courses during the 20102011 academic year. Workshop participants are compared to peers who did not enroll in the workshop for the course.

Of 133 students who initially enrolled in the Chemical Processes lecture course, 55 students withdrew without completing the course and thus used up one attempt per the two-attempt policy. However, only 13 of those withdrawing students were workshop students. When interviewed, workshop participants said they are inclined to continue in even their most difficult courses because they do not feel isolated or left behind, and they are encouraged by having the support system of peer mentors and fellow students who can help them to master the course content. They become acquainted with others in their major with whom they can study and they feel an element of peer pressure to persist so that they can succeed as a group. Workshop students express that they feel more engaged in the process of learning because they are helping each other learn.

Students who participate in workshops generally have a higher success rate than their peers who opt not to participate. One might argue that since students self-select for workshops it is not a surprise that they do better than students who don't seek out supplemental opportunities. However, average GPA for students entering workshops is not higher than that of non- 
participating students, so academic aptitude does not appear be a differentiator. The data shown in Figures 1 and 2 reflect recent results, but we have conducted workshops since the 1990's and the trends reflected above align with longer term findings.

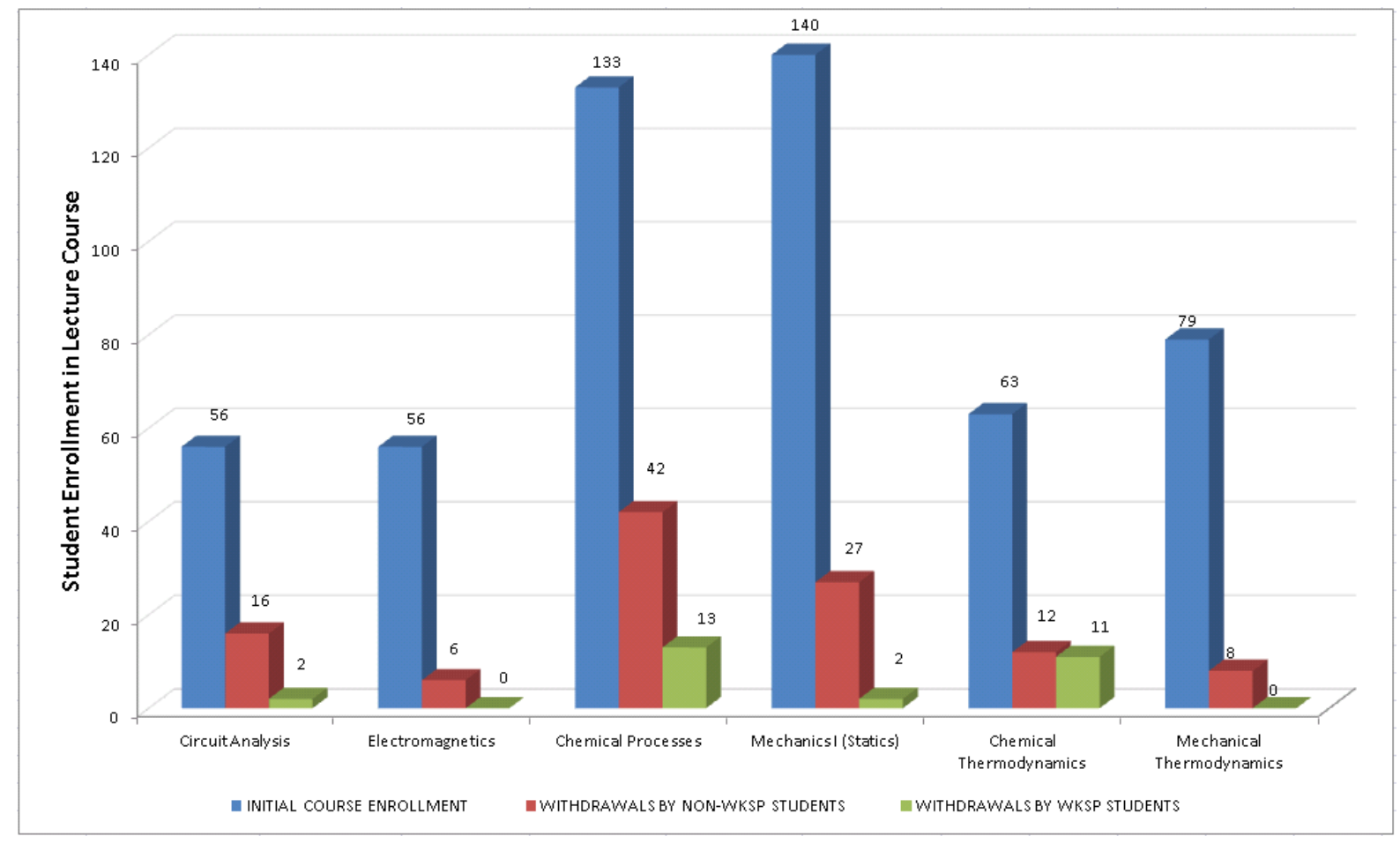

Figure 2. Lecture course enrollment at the beginning of the semester compared with subsequent course withdrawals for workshop and non-workshop students.

Data collected over 21 consecutive semesters for a typical "gatekeeper" course required of all electrical engineering majors shows that with only a few exceptions, workshop participants had higher pass rates than students taking the lecture without the workshop (Figure 3). Variances in results may reflect the differences in the skills of individual peer mentors (facilitators) because students to fill these roles are selected one semester at a time. Some facilitators continue in their role for multiple semesters, while others serve for only one semester. Thus, experience levels may vary. It is also true that different cohorts of students have distinct "group personalities" that can impact the success of the group over the course of a semester. Many times students taking these difficult sophomore engineering courses for the first time do not initially understand the level of personal commitment required to succeed in the course and take time to settle into productive study patterns, despite the counsel of their peer mentors. 


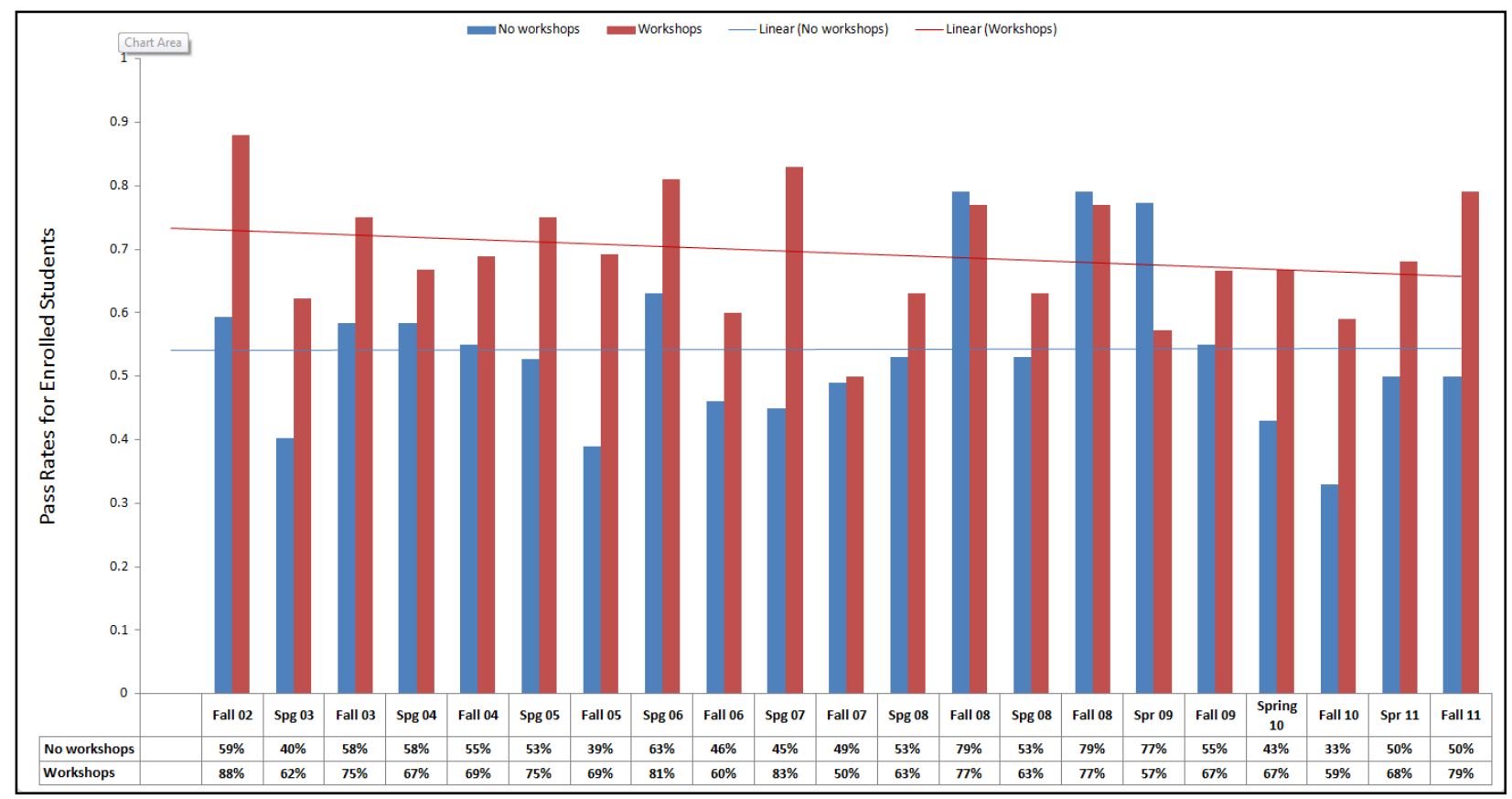

Figure 3. Pass rates for workshop and non-workshop students taking the sophomore Circuit Analysis course during the period 2002-2011.

Students who were interviewed about workshops said that they enjoyed the workshop environment of peer-teaching and they felt that regular attendance at workshop helped them to keep up with their coursework. One student (now graduated and employed at Shell Oil) summed up the sentiments of a number of respondents: "As a workshop student, I think the most valuable thing I learned from the workshops is how to strategically study in an efficient manner. I've always struggled with self-learning through reading the book and working through examples, and the workshops were geared towards collaborative studying. The benefit in that for myself was the fact that if I get stuck on a problem I used to just sit and stare at it for a long time before I felt it was all right to move onto the next problem. I entered the program a student with poor study habits and attention span, but the program helped me refocus and re-calibrate and held me accountable." Another student commented, "The workshop really helped me because it was a smaller setting than the classroom where I felt more comfortable asking for help when I didn't understand something. Workshop also made me practice more problems twice a week so I was constantly working on the material. Thanks so much for the workshop! It really helped me!"

While workshops help hundreds of engineering students to succeed in their courses, workshop facilitators (peer mentors) develop outstanding personal and professional skills through this demanding leadership role. One former workshop facilitator who graduated four years ago recently remarked that he credited his success as a project manager with ExxonMobil to the experience he gained as a workshop facilitator. He especially noted that attention to detail, time management, and the ability to explain difficult technical content were skills that he developed as a leader of workshops. Workshop facilitators develop professional and interpersonal skills that only enhance their technical acumen. We believe they excel in the workplace and become engineering leaders in their companies. 


\section{Concluding Remarks}

Our MEP community has been in existence for thirty-eight years and has served many thousands of students. One of the key tenets underpinning the philosophy of our programming is that when students are engaged in meaningful leadership and mentoring roles they are more likely to exhibit high commitment levels and develop self confidence that supports academic success. We implement this philosophy by:

- Encouraging undergraduate engineering students, especially those from underrepresented populations, to be active planners and executors of outreach and recruiting activities designed to educate youngsters about engineering. In this way, youngsters have the opportunity to spend time with college students who "look like them" and are relatable role models.

- Building a learning community in such a way that incoming students are surrounded by positive peer role models who serve as teaching assistants, outreach coordinators, workshop facilitators, and mentors. With the support of PROMES staff, student leaders emerge and gain valuable interpersonal skills while encouraging incoming students towards personal excellence.

Throughout each semester PROMES staff and faculty work with new and returning students to develop professional skills that will lead them into internships, cooperative education, and ultimately fulltime employment after graduation. Our efforts are geared toward "polishing" technically excellent students into well-rounded leaders for their generation. 